\title{
La estética de la Nouvelle Manga. La reivindicación de lo cotidiano en la nueva novela gráfica franco-japonesa
}

\author{
Jaime Romero Leo
}

Universidad de Salamanca (Departamento de Filosofía, Lógica y Estética)

Jaime Romero Leo (Cáceres, 1992) ha estudiado Filosofía en la Universidad de Salamanca en donde, además, cursó sus estudios de Máster. En la actualidad realiza su tesis doctoral en la misma universidad sobre Estética y teoría del arte japonés. Colabora para diversos medios relacionados con la cultura nipona, como la revista Eikyô. Influencias japonesas. Puede contactarse con él a través de su blog Japocomickismo.

Fecha de de recepción: 10 de noviembre de 2016

Fecha de aceptación definitiva: 13 de abril de 2017 


\title{
Resumen
}

El siguiente artículo tiene como objetivo investigar las peculiaridades estéticas de la denominada «Nouvelle Manga», corriente historietista fundada por Frédéric Boilet a principios del siglo xxi durante su estancia en Japón. Dicha corriente nace de la simbiosis de una serie de peculiaridades muy precisas de la tradición del cómic nipón y del cómic franco-europeo. Entre estas, destaca el tema de «lo cotidiano» como eje central desde el que Boilet erigió su manuscrito teórico. Ampliamente influenciados por la estética del cine francés de la llamada Nouvelle Vague, así como por el manga de autor de dibujantes consagrados en el medio nipón como lo son Jiro Taniguchi y Kiriko Nananan, entre otros, los autores de la Nouvelle Manga desarrollaron un tipo de tebeo rico en tiempos lentos, con un estilo de dibujo deudor de ambas tradiciones (la japonesa y la europea) y con unas tramas de tipo intimista y autobiográficas.

Palabras clave: Nouvelle Manga, Nouvelle Vague, Frédéric Boilet, estética, manga

\begin{abstract}
This article's aim is to study the aesthetic features of the so-called «Nouvelle Manga», which is a literary movement founded by Frédéric Boilet during his stay in Japan at the beginning of the twenty-first century. This literary movement was born due to the symbiosis of some specific features of the Japanese and of Franco-European comic. Since Boilet's theory, the 'daily life' is highlighted as the cornerstone among these features. The authors of the Nouvelle Manga were highly influenced by both the aesthetic of the French cinema named Nouvelle Vague and the Manga of devoted Japanese cartoonists like Jiro Taniguchi and Kiriko Nananan, among others. They developed a slow-time comic with a drawing stlyle clearly biased by both traditions (the Japanese and the European) and with intimist and autobiographic plots.
\end{abstract}

Key words: Nouvelle Manga, Nouvelle Vague, Frédéric Boilet, Aesthetics, manga

\section{Cita bibliográfica}

Romero Leo, J. «La estética de la Nouvelle Manga. La reivindicación de lo cotidiano en la nueva novela gráfica franco-japonesa», en CuCo, Cuadernos de cómic n. o 8 (2017), pp 83-101. 


\section{La importancia de lo cotidiano en el nuevo cómic franco-japonés}

A principios de la década de 1980 fueron varias las editoriales europeas dedicadas al cómic que comenzaron a centrar el foco de interés únicamente en el factor económico. Es decir, en las ventas. ${ }^{1}$ Las editoriales querían productos sencillos de elaborar y rápidos de vender. Para ello se recurrió a las manidas fórmulas del superhéroe, la aventura y la ciencia ficción que ya habían funcionado en el pasado. El contexto propiciado por la irrupción de los mercados en las editoriales se extendió a lo largo de la segunda mitad del siglo pasado hasta que, en 1990, factores clave como el abaratamiento de los medios de impresión y producción, la creación de editoriales que apostaran por conceder una mayor libertad creativa a sus dibujantes y el auge, cada vez más acuciado, de autores que reivindicaban un tebeo que hablase sobre ellos mismos, sobre su vida y su día a día, dieron finalmente lugar a la aparición del denominado «cómic de autor»o «novela gráfica». ${ }^{2}$

En la década de los noventa surgieron obras tan representativas como la consagrada Maus (finalizada y compilada en 1991) de Art Spiegelman, abriendo la veda finalmente hacia lo biográfico y autoficcional, ${ }^{3}$ pero también incluyendo dentro de sí a lo psicológico e histórico tal y como pudo observarse en otras obras tan significativas como Persépolis de Marjane Satrapi en 2000-2003 o Epiléptico. La ascensión del gran mal de David B. en 1996-2003. ${ }^{5}$ En nuestro país, Arrugas (2007) de Paco Roca o Miércoles (2012) de Juan Berrio ${ }^{7}$ seguían

${ }^{1}$ En su «Manifiesto Nouvelle Manga», Frédéric Boilet consideró este uno de los principales factores que limitó las posibilidades del cómic como medio creativo. Boilet, F. «Manifiesto Nouvelle Manga» (2001). Disponible en http://www.boilet.net/es/nouvellemanga manifeste 1 (Consultado el 7 de marzo de 2016).

${ }^{2}$ Las vicisitudes que dieron pie a la creación de un cómic dirigido a público adulto que sentó las bases para ser reconocido como medio artístico a tener en cuenta dentro del panorama intelectual, fueron tratadas en la primera de las ponencias del ciclo «Del tebeo a la novela gráfica. El cómic y sus relaciones con la literatura y el cine», organizado por la fundación MAPFRE el 27 de septiembre de 2011 por el escritor Martín Casariego, el crítico y autor Álvaro Pons y el renombrado filósofo Fernando Savater. Disponible en https://www.youtube. com/watch?v=ilvaPm7AeD4 (Consultado el 2 de octubre de 2016).

3 Los estudios literarios con respecto a la novela gráfica sitúan a esta como uno de los máximos exponentes de la autoficción en el siglo xxi. Es interesante observar la reivindicación de las posibilidades del cómic hecha desde campos como el de la filología y la literatura. Cfr. Agustí Farré, A. «Autobiografía y Autoficción», en Sociedad Española de Estudios Literarios de Cultura Popular, n. 6 (2006), pp. 14-15.

${ }^{4}$ Satrapi, M. Persépolis. Trad. Albert Agut. Barcelona, Norma, 2007.

${ }_{5}^{5}$ David B. Epiléptico. La ascensión del gran mal. Trad. Lorenzo Fernández Díaz. Madrid, Sinsentido, 2009.

${ }^{6}$ Roca, P. Arrugas. Bilbao, Astiberri, 2007.

${ }^{7}$ Berrio, J. Miércoles. Madrid, Sins Entido, 2012. 
la estela trazada hacia el tema de la realidad cotidiana, demostrando como la representación de la vida ordinaria podía resultar igual de sugerente que las corrientes del mainstream.

Los propios autores eran conscientes de qué temáticas querían abordar en sus obras, sobre qué querían hablarles al lector. Cansados de un mainstream que ya no les «interrogaba», hicieron suyos el «grito» de indignación que Campi y Zabus materializaban en el prólogo de su obra Gente corriente:

Basta con llevar una vida discreta para que la gente se comporte como si uno no estuviese ahí. ¡Pero existimos, maldita sea! ${ }^{8}$

En Los combates cotidianos del ya consagrado Manu Larcenet se reivindicaba en términos similares el combate, el valor, la audacia, la fuerza del guerrero... Ahora bien, este batallador no era otro que un padre primerizo con miedo a serlo y sus luchas no eran otras que las luchas a las que cualquiera debe enfrentarse en su día a día:

Un ataque de ansiedad. Poner una lavadora. Buscar empleo. Huir del ruido de la ciudad. Tender la ropa. Padre enfermo. Hacer de canguro de tu sobrina. Tu pareja y tú. Buscar una casa. El trabajo... Cada día hay una nueva lucha, cada día un nuevo combate. ${ }^{9}$

En la citada obra de Berrio, por mencionar un ejemplo de la herencia francesa en la producción española, podía leerse la sentencia:

Un miércoles cualquiera la aventura diaria nos espera a la vuelta de la esquina. Una comunidad de vecinos, un barrio, una ciudad. Vidas que se cruzan y se descruzan, hilos invisibles de una telaraña [...] Miércoles es una historia donde parece que no sucede nada y sin embargo ocurren muchas cosas: cosas pequeñas y cosas grandes. Porque nuestras pequeñas rutinas pueden ser tan apasionantes como una novela policíaca. Y porque lo cotidiano no es otra cosa que lo maravilloso. ${ }^{10}$

Al igual que estos, existen múltiples ejemplos más que muestran la tónica que las obras pertenecientes a la novela gráfica han asumido de manera general en Europa. Una de las editoriales a las que el actual paradigma del tebeo debe su porqué es la francesa L'Association, fundada en 1990. De entre la prolífica afluencia de dibujantes franceses que surgió en torno a aquellos años, uno en particular destacó en el panorama nacional de la bande desinée, pero, curiosamente, también en el del manga japonés: Frédéric Boilet. Fue uno de los hijos de este

${ }^{8}$ Campi, T. y Zabus, V. Gente corriente (Epílogo).Trad. Natalia Mosquera Sarmiento. Barcelona, La Cúpula, 2014.

9 Larcenet, Manu. Los combates cotidianos (Epílogo). Trad. Enrique Sánchez Abulí. Barcelona, Norma, 2012.

10 Berrio, J. Miércoles (Epílogo). Madrid, Sins Entido, 2012. 
contexto histórico que se embarcó hacia los horizontes de lo cotidiano. Años después de formar su nueva corriente, la Nouvelle Manga, el historietista recordaría aquellos años como los que propiciaron la aparición de un género como el suyo:

Con la aparición de editoriales como L'Association o Ego comme X, nació en Francia, a principios de los años noventa, un movimiento precisamente como reacción a la $\mathrm{BD}^{11}$ de ciencia ficción, héroes y acción para adolescentes de los años ochenta. Proponiendo historias basadas en la vida cotidiana (sean autobiográficas o ficticias) en un estricto formato de 46 páginas a color y viñetas en serie, estas editoriales y sus autores abrieron la $\mathrm{BD}$ a nuevos lectores, demostrando que la $\mathrm{BD}$ no estaba condenada al mercado exclusivo de los fans de BD, buscadores de aventuras, de fantásticas y complacientes falsas imágenes. ${ }^{12}$

Si hemos de destacar alguna de las actitudes que han llevado al cómic a ganar la solidez que hoy está obteniendo como medio de expresión, además de su viraje hacia el tema de lo cotidiano como eje de sus historias, esta es la de la búsqueda del intercambio cultural propiciado por los préstamos estilísticos y teóricos que las grandes corrientes del tebeo se proporcionan entre sí. El primer gran mercado del cómic mundial en institucionalizar estos intentos de recepción estilística fue Japón y, en particular, la editorial Kodansha, a través de su beca Morning Manga Fellowship. El objetivo era el de importar a dibujantes extranjeros con el fin de aprender de ellos e integrarlos dentro de su propio sistema historietista. El primer europeo en recibirla fue Frédéric Boilet en 1993.13

Es interesante observar cómo dicha recepción cultural del exterior nunca ha supuesto un problema aparente para el país nipón, el cual, ya sea en materia religiosa, artística o social, ha integrado perfectamente las influencias recibidas dentro de sí. Aún hoy, la actitud que llevó a becar a literatos como Natsume Sōseki para viajar y aprender de Europa o contratar a profesores occidentales como Lafcadio Hearn a finales del XIX para dar clases en Japón ${ }^{14}$ continúa repitiéndose en ejemplos como el de la dotación económica concedida a Boilet con el fin de asumir e integrar parte de su tradición como historietista europeo. A través de dicha beca, pudo permanecer un año en Japón (que se convertiría en más de

\footnotetext{
${ }_{11}$ Para un recorrido historiográfico que recoja las circunstancias que propiciaron la evolución del tebeo francobelga, así como el desarrollo de algunas de las características más importantes y obras cumbre del género, cfr. Groensteen, T. La bande dessinée: Une littérature graphique. Toulouse, Éditions Milan, 2005. Si esta investigación se centra en la región francófona se debe a que es considerada la más influyente del continente en cuanto al mundo del cómic. A pesar de ello deben remarcarse las influencias recibidas de tradiciones historietistas como la española o italiana. Cfr: Mazur, D. y Alexander, D. Cómics. Una historia global, desde 1968 hasta hoy. Trad. Antonio Díaz Pérez. Barcelona, Blume, 2014, pp. 154-164.

12 Boilet, F. (2001). Op. cit.

13 Cfr. Mguyén, L. «Entretien paru dans», en Anime Land n.o 43 (1998). Disponible en http://www.boilet. net/fr/animeland 01.html (Consultado el 12 de febrero de 2016).

${ }_{14}$ A su vuelta de Inglaterra, Natsume Sōseki ocuparía el puesto en la universidad que ostentaba Lafcadio Hearn. Cfr. PAzo, J. «Natsume Sōseki, el humilde campeón de las letras japonesas», en Cid Lucas, F. (ed.). La narrativa japonesa: Del Genji Monogatari al manga. Málaga, Cátedra, 2014, p. 133.
} 
una década de residencia en el archipiélago), ${ }^{15}$ creando junto a Benoît Peeters la que sería la primera obra de su nuevo género: Tokio mi jardín (1997). En relación a esta, Boilet explicaba:

J'avais reçu la bourse et jeetais venu pour trouver la matière à l'histoire d'un Français à Tôkyô, et c'est donc ce sujet que j'ai proposé simultanément à Morning et À Suivre après quelques semaines de séjour. Si l'idée avait été bien accueillie par À Suivre, elle a été immédiatement jugé ennuyeuse par les gens de Morning: «PPourquoi ne feriez-vous pas plutôt l'histoire, beaucoup plus amusante, d'un Japonais à Paris?» M'ont-ils proposé lors d'une petite reunión. Morning m'avait accordé une bien belle bourse pour une année entière de recherches sur la vie à Tôkyô, mais me proposait après quelques semaines de travailler exactement sur l'inverse! C'était évidemment impossible, et je n’ai pas donné suite à la proposition. ${ }^{16}$

Como se observa en las declaraciones de Boilet, las intenciones de Kodansha por «absorberlo» se invirtieron, siendo Boilet el que absorbió a Japón. A través del contacto con el archipiélago, los intentos del historietista europeo por desarrollar de manera más explícita la temática de lo cotidiano de la que la novela gráfica ya se hacía eco en líneas generales, encontraron acogida en ciertos dibujantes japoneses que rápidamente conectaron estilísticamente con las propuestas del francés. Entre ellos destacan: Kiriko Nananan, Jiro Taniguchi, Moyoko Anno, Aurélia Aurita (camboyana), Little Fish o Taiyo Matsumoto. Desde Francia fueron también varios los dibujantes que decidieron unirse al embrión de la nueva corriente que comenzaba a fraguarse, con David B., Emmanuel Guibert, Benoît Peeters y Joann Sfar como algunos de los nombres más representativos. ${ }^{17}$

Las influencias del cine francés de los años sesenta del pasado siglo recogidas en su obra, así como la fusión de la técnica ilustrativa de la escuela franco-belga con la de la estética del manga, hicieron que rápidamente su nueva corriente fuese bautizada como Nouvelle Vague Manga por Kiyoshi Ksumi, editor de la revista Comickers. Boilet consideró que el nombre englobaba a la perfección las pretensiones para con la vida cotidiana que intentaba plasmar en sus historias, por lo que decidió hacerla suya reduciéndola a Nouvelle Manga ${ }^{18}$ Tanto las influencias filmográficas como la recepción de los valores estéticos de la tradición japonesa, que aún perviven en el imaginario de ciertos mangakas contemporáneos como los citados Kiriko Nananan y Jiro Taniguchi, entre otros, propiciaron que Boilet decidiese desarrollar su movimiento historietista en base a la representación de la vida cotidiana. (FIG. 1)

${ }_{15}$ Cfr. Boilet, F. L'Apprenti Japonais. Bruselas, Les Impressions nouvelles, 2006, p. 15.

${ }^{16}$ Cfr. Batisde, J. «Entretien avec Frédéric Boilet», entrevista realizada entre París y Tokio de octubre a diciembre de 2001. Disponible en http://www.boilet.net/fr/nouvellemanga bilan 1.html (Consultado el 3 de octubre de 2016).

${ }^{17}$ Las colaboraciones entre algunos de los dibujantes nipones y franceses pertenecientes a la Nouvelle Manga se hicieron efectivas en Boilet, F. (ed.). Japón visto por 17 autores. Barcelona, Ponent Mon, 2005.

${ }^{18}$ Hernández Ranza, o. «Nouvelle Manga, mon amour. Reflexiones sobre la narración gráfica de historias cotidiana», en Ballaterra Journal of Teaching and Learning Language and Literature, n. 2 (2010), p. 41. 

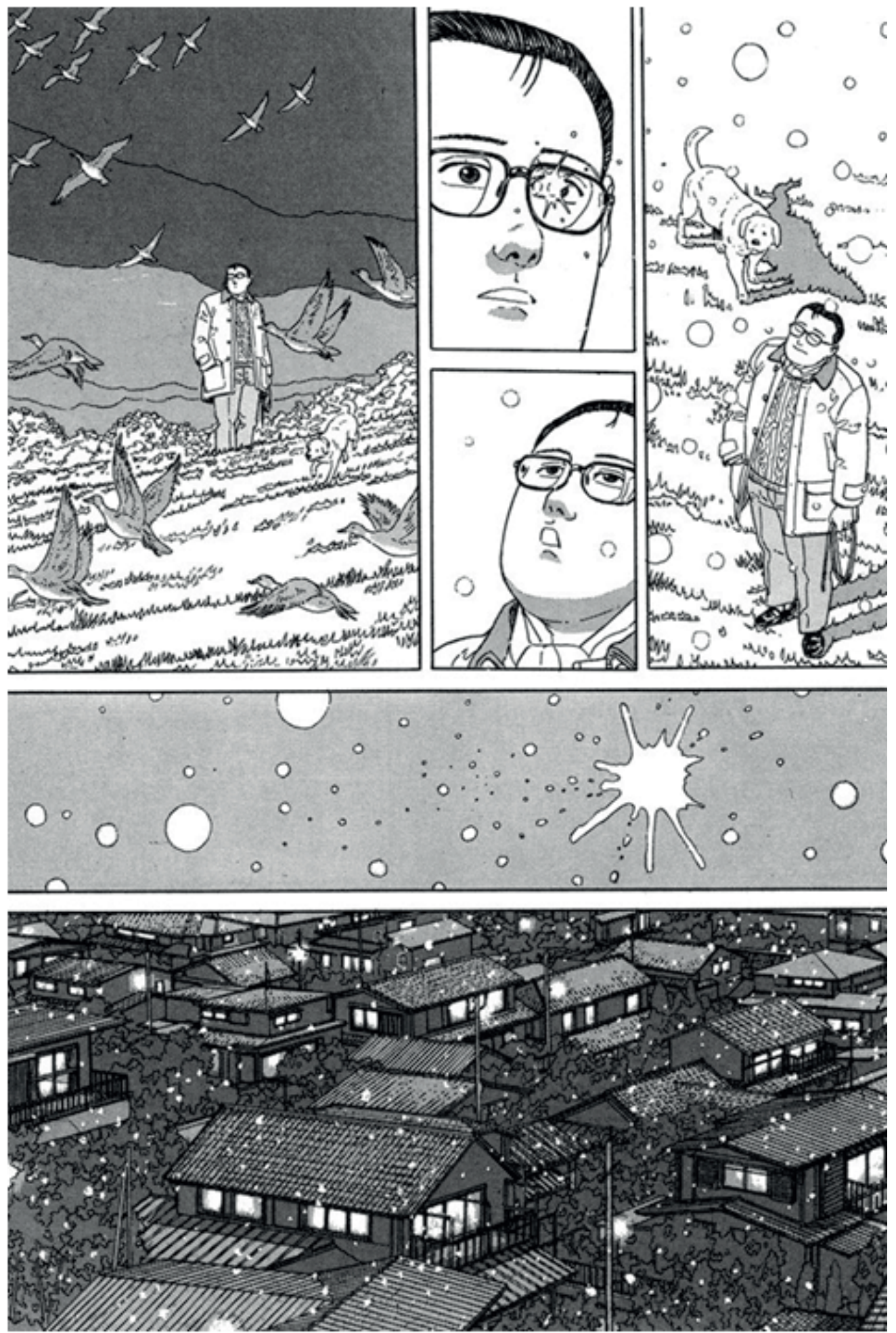

FIG. 1. Taniguchi, J. El caminante. Trad. S. Shimoyama, Miguel Angel Ibáñez, Víctor Illera y Ana Millán. Barcelona, PonentMon, 2015, p. 16. 


\title{
Me llamarán «el caminante» \\ Primer chubasco \\ Matsuo Bashō
}

\section{La estética de la Nouvelle Manga}

Cuando Boilet tomó contacto con los autores nipones cuyas obras se alejaban del manga comercial quedó sorprendido por esta sensibilidad especial para con la vida cotidiana que reflejaban en sus tebeos. Taniguchi, Takahama, Matsumoto y Nananan entre otros habían desarrollado un cómic alternativo, sobrio y sosegado. (FIG. 2)

Ese tebeo era el que Boilet quería para Europa, y no las corrientes mainstream que, debido a los cuantiosos beneficios económicos que suponían para los mercados del cómic, eran las únicas que llegaban a Occidente:

\begin{abstract}
Casi toda la manga ${ }^{19}$ que se ha traducido al francés en los últimos diez años ha sido manga comercial dirigida a adolescentes, como consecuencia de las series de animación que les habían precedido en las pantallas francesas. Mostrando temas de aventuras, ciencia ficción, protagonizados por héroes... Como en Japón, este tipo de manga tan específico genera su propio fenómeno otaku: prensa especializada, cosplay (Costume play: concurso de disfraces), etcétera. Cierto número de manga sobre la vida cotidiana también es traducida, pero de nuevo va dirigida a adolescentes, con la vida cotidiana tratada a menudo con sobredramatismo o de forma caricaturesca: una vida cotidiana parecida a la de Hélène et les garçons o a las telenovelas domésticas de la televisión japonesa, en vez de a Cada uno busca su gato u Omobide Poroporo. ${ }^{20}$
\end{abstract}

\footnotetext{
${ }_{19}$ Boilet ha defendido en numerosas ocasiones el uso original que Katsushika Hokusai, creador del término, implantó. Hokusai denominó a la recopilación de los grabados que creó entre 1814-1849 La Manga (Man= trazo rápido o garabato. $G a$ = dibujo). Respecto al porqué del uso histórico del término, Boilet explica: «Habiendo solo sido usado en los medios de comunicación franceses desde hace pocos años, la palabra "manga" es, desafortunadamente, percibida todavía de manera muy estereotipada, tanto por el público como por los medios de comunicación. "el" manga es, en su forma masculina, una abreviatura de un cómic japonés vulgar para niños y adolescentes, que es simultáneamente violento y pornográfico: el equivalente japonés a los sórdidos comics que, antiguamente, se importaban de Italia. Ya sabemos, por experiencia con nuestra BD y nuestros "comics", que los estereotipos son casi imposibles de eliminar una vez que se han visto asociados con un término. ¡Es por eso por lo que propongo burlarles! Usando las raíces históricas y sociológicas de la versión femenina de la palabra "manga", creo que será posible cambiar su percepción pública. Además de "el" manga, esencialmente, comics japoneses para un público compuesto en su mayoría por adolescentes, está "la" manga, haciendo referencia a los comics japoneses de autor, adultos y universales, que hablan de hombres y mujeres y su vida cotidiana: una manga más cercana a, por ejemplo, las películas de Yasujirô Ozu y Jacques Doillon o a las novelas de Yasushi Inoue que a Sailor Moon o Luc Besson». вorlet, f. (2001). Op. cit. Una vez desglosada la explicación de Boilet, debemos aclarar que este artículo utilizará la terminología popular que designa al manga en su forma masculina debido a que la mayoría del análisis girará en torno a las obras de corte «cotidiano» a las que Boilet refiere. En esta ocasión no será necesario hacer una diferencia entre el manga de autor y las corrientes mainstream, debido a que este trabajo tan solo se centrará en los cómics del primer grupo.
}

20 Idem. 


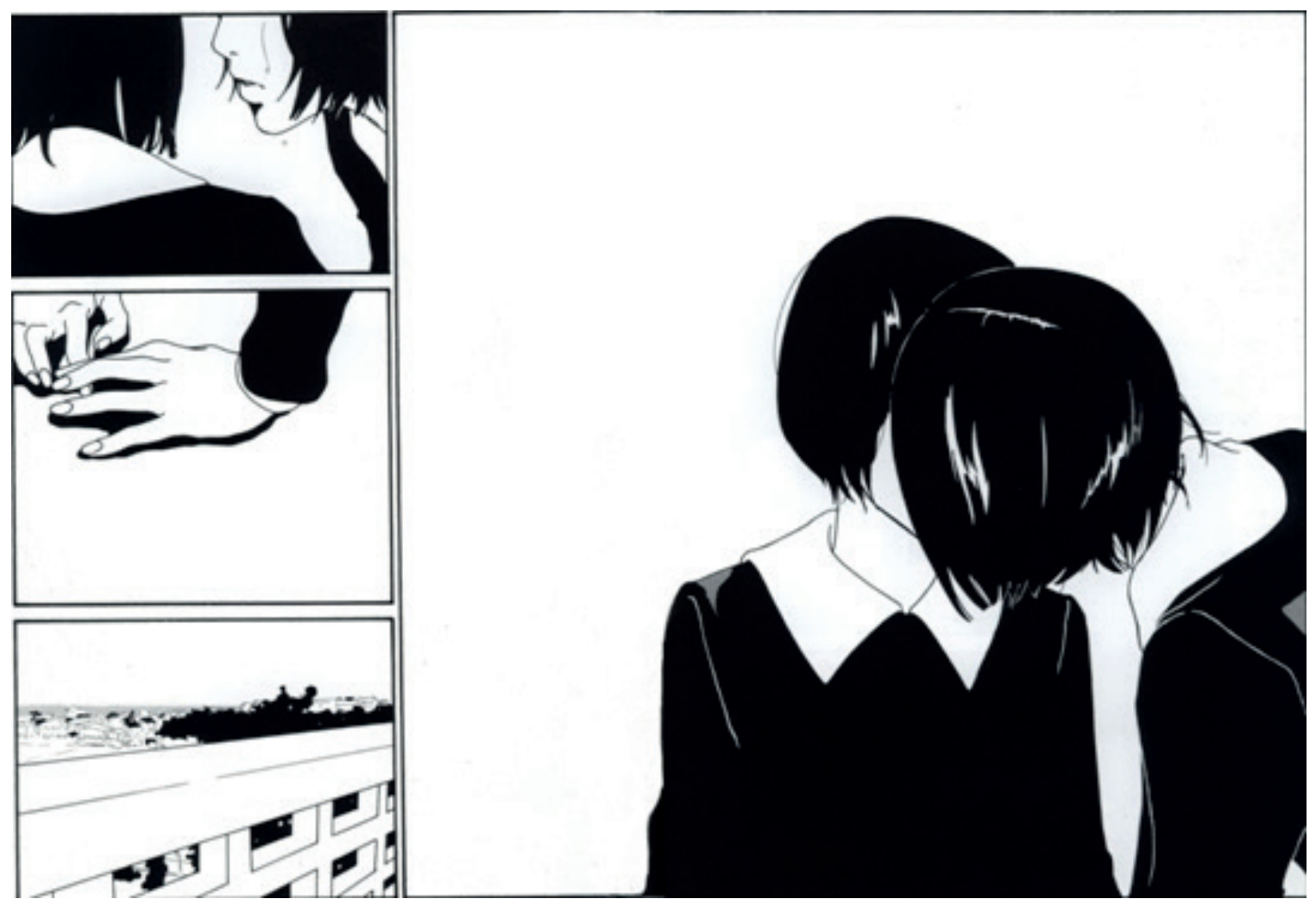

FIG. 2. Nananan, K. Blue. Trad. Xavier Hérbet y Naomiki Satô. Tarragona, PonentMon, 2004, pp. 70 y136.

El nuevo género desarrollado por Boilet permitía una simbiosis entre los estilos del cómic franco-europeo y el japonés. El francés observó que las historias contadas por el cómic europeo eran demasiado infantiles, poco elaboradas, previsibles... Al mismo tiempo que criticaba el guion, Boilet reflexionó en torno al hecho de que la mayoría de los dibujantes se hubieran forjado en las escuelas de bellas artes del continente o hubiesen bebido de las influencias ilustradoras de estas. ${ }^{21} \mathrm{Si}$ algo había de destacarse del cómic producido en Europa, según su criterio, era el estilo de dibujo caracterizado por su gran calidad gráfica. Lo contrario ocurría en Japón, donde el estilo de la ilustración no podía competir con las cotas artísticas alcanzadas en Occidente, ${ }^{22}$ pero donde las historias gozaban de gran

${ }^{21}$ En relación a los estudios realizados a partir de las conexiones establecidas entre el arte y la novela gráfica caben destacar análisis como La pintura en el cómic en el ámbito de lo histórico-formal así como Denotando acontecimientos. Arte y destrucción en la novela gráfica en el de la Estética y Teoría de las Artes. Cfr. GAsca, L. y Mensuro, A. La pintura en el cómic. Madrid, Cátedra, 2014 y Hernández Sánchez, D. «Denotando acontecimientos. Arte y destrucción en la novela gráfica», en Revista de Occidente, n. ${ }^{2} 429$ (2017).

${ }^{22}$ La principal causa es el complejo y multimillonario aparato comercial que se ha construido en torno al manga japonés. Las exigencias de las editoriales por publicar mensual e incluso semanalmente en las revistas de las que, meses más tarde, se realizarán las recopilaciones que saldrán a la venta, obligan a la repetición de fórmulas estilísticas que hasta ahora han funcionado y que son rápidas de repetir con el fin de ceñirse a los plazos de entrega. Es esta una de las causas de que el cómic japonés sea tan fácilmente reconocible. A grandes 
atractivo. ${ }^{23}$ Los europeos sabían cómo dibujar historias, y los japoneses cómo y sobre qué narrarlas:

Lo que inmediatamente me impresionó fue la cantidad de manga que trataba sobre la vida cotidiana. La manga, sus obras, sus autores, sus lectores, me demostraron que, al igual que la literatura o el cine, las historias gráficas pueden hablar de hombres y mujeres, de la vida cotidiana, y aun así atraer a muchos lectores. Todavía mejor, descubrí que era gracias a ello que el público de la manga japonesa era tan amplio y variado: que no estaba limitado solo al otaku, en oposición a los lectores de BD en Francia, que suelen ser aficionados al medio. Me di cuenta de que lo que llevaba años queriendo hacer en la BD existía en la manga desde el principio, de manera que no solo se ha convertido en una fuente inagotable de inspiración, sino que ahora también, Japón es para mí una favorable base desde donde crear y publicar mis historias... Esta es la causa de que, cuando un lector o un periodista japonés me dice que yo hago Nouvelle Manga, le respondo que no soy el único, ya que mi trabajo se inspira en, o tiene afinidades con, otros manga de autores como Yoshiharu Tsuge, Naito Yamada, Kiriko Nananan, Yoshitomo Yoshimoto y muchos más... ${ }^{24}$

Lo cotidiano será, pues, el punto de encuentro desde donde Boilet realizará la fusión. Ahora bien, una vez mostradas algunas de las características de la estética nipona asumidas por el tebeo japonés que reafirman la posibilidad de reivindicación de lo cotidiano, queda hacer lo propio con la parte franco-europea. Debe recordarse que la intención de Boilet es la creación de un género que se nutra por igual tanto de la tradición japonesa como de la europea. Así, conjugará la especial sensibilidad para con lo cotidiano expresada por el pueblo nipón con la tradición cinematográfica de su país; en particular, con la del tipo de cine creado en la década de 1960: la denominada Nouvelle Vague.

Boilet advierte que la relación que quiere lograr entre Francia y Japón sitúa un importante punto de encuentro en el medio cinematográfico. El segundo país que más cine francés consume, después de la propia Francia, es Japón. Sin ir más lejos, en el 2000, coincidiendo con las fechas de la creación de su movimiento, los filmes franceses habían atraído a más de 2,6 millones de espectadores en el archipiélago nipón. Boilet, conocedor de estos datos, vio en los receptores del cine de la Nouvelle Vague, así como de sus herederos, un potencial grupo de lectores para su nuevo género tanto en Europa como en el propio Japón. Dado que las premisas estilísticas del fundador de la Nouvelle Manga provienen estrictamente de las influencias de la producción cinematográfica realizada en Francia, tan solo se tratará aquí al nuevo cine francés de los sesenta dejando al margen la corriente surgida en Japón durante estos años setenta como reacción al cine de Godard y Truffaut. A pesar de que es probable que gran parte de los dibujantes (por la parte nipona) adheridos a la Nouvelle Manga estuviesen influidos de una manera u otra por los filmes creados durante estos años en Japón, la toma de esta decisión se conforma en base a la premisa de que la corriente Novelle Vague

rasgos (con sus obvias excepciones, como en el caso de los títulos pertenecientes a la Nouvelle Manga) todos los mangas parecen iguales. Para más información acerca del tema, cfr. Berndt, J. El fenómeno manga. Trad. J. A. Bravo. Barcelona, Martínez Roca, 1996, p. 18.

${ }^{23}$ Hoy en día existe manga sobre cualquier tema imaginable: dedicado a las amas de casa, para los oficinistas, universitarios, colegiales, profesores, deportistas, manga de contenido histórico, dedicado a la repostería, papiroflexia, artes marciales... Cfr. Berndt, J. Op. cit., p. 22.

${ }^{24}$ Boilet, F. (2001). Op. cit. 
Japonaise o Naburu Bagu no ha sido considerada más que como una manera de aglutinar bajo una misma denominación a un grupo de directores japoneses que, influidos en cierta manera por la Nouvelle Vague, crearon durante finales de los años sesenta y principios de los setenta ciertas obras que recordaban vagamente a las producidas por el nuevo cine francés. ${ }^{25}$ Dentro de la Nouvelle Vague Japonaise, a diferencia de lo acontecido en Francia, nunca existió un sistema teórico con el que el conjunto de los directores, que se suponía la conformaban, se sintieran identificados. La repercusión de esta «corriente» fue muy limitada tanto a nivel nacional como internacional en comparación a la Nouvelle Vague Française. ${ }^{26}$ Así, dado el alto grado de interés que la Nouvelle Vague francesa causó en el pueblo nipón, el acercamiento a parte de las influencias que se establecieron entre esta corriente del cine francés y la sensibilidad que envuelve a cierto grupo de dibujantes japoneses puede realizarse aun dejando de lado a la controvertida Nouvelle Vague Japonaise.

Una vez realizada la matización debemos advertir que las influencias recibidas por Boilet de la Nouvelle Vague no solo repercutieron en su estilo de dibujo (FIG. 3), ${ }^{27}$ sino que también causaron un gran impacto a nivel teórico en sus propias concepciones con respecto a lo que consideraba que debía ofrecer el cómic:

Je ne me réclame pas de François Truffaut, je n'ai ni sa caution ni sa bénédiction! Mais je le cite souvent, c'est vrai. Comment faire autrement avec un artiste de cette envergure? En tant que cinéaste, critique et théoricien, François Truffaut a peu d'égal, ses films et ses écrits sont une constante source d'inspiration pour moi. [...] Je ne me suis pas lancé dans l'aventure Nouvelle Manga par plaisir mais seulement par devoir, et parce que personne ne fait rien. ${ }^{28}$

Bajo la premisa de que la Nouvelle Manga nacía no de su interés o inquietudes como autor («Tout le temps, toute l'énergie consacrés à la Nouvelle Manga sont pris sur mes activités d'auteur, et franchement je m'en passerais bien!»), ${ }^{29}$ sino de un deber como historietista para

${ }_{25}$ Para más información acerca de la Naburu Bagu, cfr. http://desistfilm.com/naburu-bagu-o-como-deslindar-de-godard-la-mentira-de-la-nueva-ola-japonesa/ (Consultado el 5 de abril de 2016).

${ }^{26}$ A pesar de lo argumentado, ha de matizarse con respecto al nuevo cine japonés que ciertas influencias de la Nouvelle Vague, así como del resto de los nuevos cines que comenzaron a surgir tras este, fueron retomadas por el cine japonés de las décadas de los ochenta y noventa, y que hoy, Japón cuenta con un interesante compendio de directores entre los que destacaríamos a Naomi Kawase, Takeshi Kitano, Hirokazu Kore-Eda o Kiyoshi Kurosawa entre otros, que han hecho suyas varias de las premisas promulgadas por el Cinema d'autor. Para un acercamiento a la nueva ola del cine contemporáneo japonés véanse las obras: LARDín, R. El principio del fin: Tendencias y efectivos del novísimo cine japonés. Barcelona, Paidós Ibérica, 2003; y LóPEz, J. M. (ed.). Naomi Kawase. El cine en el umbral. Madrid, T\&B editores, 2008.

27 A pesar de que el francés nunca ha reconocido que alguna de sus obras haga referencias explícitas a escenas concretas de las películas de sus directores favoritos, las relaciones entre viñeta-fotograma pueden establecerse rápidamente.

${ }^{28}$ Cfr. Batisde, J. «Entretien avec Frédéric Boilet» entrevista realizada entre París y Tokio de octubre a diciembre de 2001. Disponible en http://www.boilet.net/fr/nouvellemanga bilan 1.html (Consultado el $11 \mathrm{de}$ febrero de 2016).

29 Idem. 

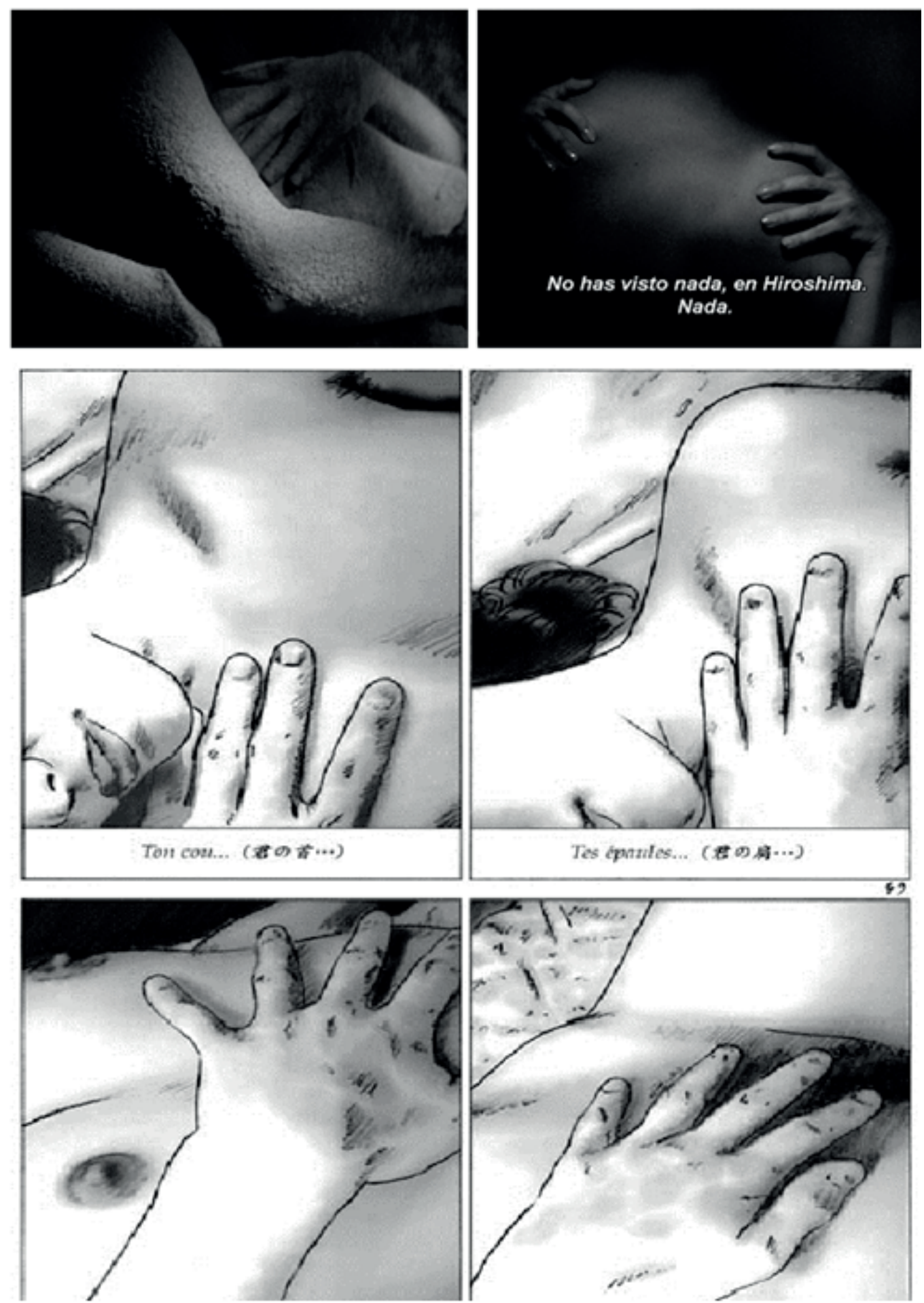

FIG. 3. Resnais, A. Hiroshima, mon amour,

1967; y Boilet, F. La espinaca de Yukiko, Trad.

Enrique Sánchez Abulí. Tarragona, Ponent

Mon, 2003, p. 45. 
con el tipo de cómic que, pensaba, debía comenzar a realizarse dado el viraje hacia la vida cotidiana que la novela gráfica había posibilitado, se desligan interesantes relaciones con respecto a la reacción que los jóvenes críticos de la revista Cabiers du Cinéma promulgaron frente al «cine de papá» o «cine de qualitê». ${ }^{30}$ Boilet matizaba las intenciones de su movimiento afirmando que su tebeo marchaba no tanto contra el cómic de «papá» como contra el comercial:

Le Manifeste de la Nouvelle Manga n`est pas un manifeste contre la «bande dessinée de Papa»: nombre d'auteurs de talent ne mont pas attendu, depuis dix ans et même dans les années 80 , pour se bagarrer, parfois avec brio, contre la bande dessinée commerciale «qualité France» Ce sont plutôt «les traductions de Papa» que mon texte vise, sur un terrain international franco-japonais où les décisions éditoriales des uns sont essentiellement guidées par les succès de vente des autres, les vraies informations finalement rares et les contradicteurs quasiment aphones.

Gracias a su salto evolutivo hacia la novela gráfica, el cómic había logrado tras la década de los noventa no solo el afianzamiento de esta política de autor que en los sesenta ya se respiraba en el mundo del cine, sino también alcanzar el rango de verdadero lenguaje artístico al que el resto de formas de expresión como la fotografía, la pintura o la literatura habían llegado. Las premisas de Austruc ${ }^{31}$ o Truffaut ${ }^{32}$ respecto a la reivindicación de la cámara como el pincel del pintor o la pluma del escritor, esto es, como medio desde el que poder expresar del mismo modo que el resto de manifestaciones, estaban siendo asumidas por el tebeo a principios del siglo XXI.

$\mathrm{Al}$ igual que las proclamas promulgadas por los defensores del cine de autor, en el mundo de la historieta se argumentó que todo podía representarse a través de la viñeta. No había escena de película, párrafo o vivencia que no pudiera ser expresado dentro de los cánones que caracterizan al medio gráfico de la historieta. ${ }^{33}$ Este logro del tebeo debió gran parte de su éxito a que, al igual que los pronósticos de Austruc con respecto a la segmentación del gran y unitario «Cine» en "pequeños cines» dedicado a la representación de casi cualquier parcela de la realidad, ${ }^{34}$ el gran y único cómic comercial dio paso a las múltiples variaciones representacionales y temáticas que la novela gráfica permitía. Podía hacerse cómic de todo

30 Cfr. Angulo, J. «Antes de la revolución. El cine francés de 1944 a 1954», en F. Heredero, C. y MontenDER, J. E. (ed.). En torno a la Nouvelle Vague. Rupturas y horizontes de la modernidad. Valencia, Festival internacional del cine de Gijón ediciones La Filmoteca, 2002, pp. 86-91.

31 Cfr. Austruc, A. «Camera stylo L’Ecran Francais», no. 144 (1948), en Romaguera i Ramió, J. Fuentes y documentos del cine. Barcelona, GG Mass media, 1980, pp. 206-207.

32 Cfr. Zunzunegui, S. «La "política de autores” y la noción de "puesta en escena” en los Cabiers du Cinéma entre 1952 y 1965», en F. Heredero, C. y Montender, J. (eds.). Op. cit., p. 64.

${ }_{33}$ Respecto a las posibilidades creativas que ofrece el medio del cómic así como de las maniobras usadas por los dibujantes a la hora de plasmar sentimientos, de cómo imprimir velocidad, de las diferencias y posibilidades entre la representación hiperrealista o caricaturesca, etcétera., cfr. McCloud, S. Entender el cómic. El arte invisible. Trad. Enrique Sánchez Abulí. Bilbao, Astiberri, 2009, pp. 31-53.

${ }^{34}$ Cfr. Austruc, A. Op. cit. pp. 206-207. 
y sobre cualquier cosa, pero serían particularmente las historias sacadas de la vida corriente de sus autores las que primarían con respecto al resto de temáticas.

La relación entre vida y cine que planteó la Nouvelle Vague también fue recuperada por el tebeo en su relación entre vida y viñeta. Una de las anécdotas que más se han citado en torno a la figura de Godard ha sido la de cómo el director dejaba encendida su cámara en los momentos de descanso para filmar a sus actores interactuando entre sí del modo más natural y orgánico posible. Tras la proyección de Dans le noir du temps, su contribución al filme colectivo Ten minutes older: The cello en 2002, el francés explicaba en relación a ello que existían dos recorridos a lo largo de la cámara: de la lente al visor y del visor a la lente. La Nouvelle Vague, dentro de sus posibilidades, habría tratado de seguir el segundo camino. ${ }^{35} \mathrm{~A}$ través de la historieta, Boilet intentaría hacer lo propio para el cómic (FIG. 4).

Los sentimientos en torno a lo cotidiano, como el cansancio o la melancolía, permiten una apertura al mundo tal y como han defendido algunos autores; nos ayudaban a tomar conciencia de nosotros mismos a través de la conciencia de la presencia del otro en el que, al fin, tras salir de nuestro narcisismo existencial, reparamos. ${ }^{36}$ La cotidianidad, la realidad, penetra en la obra de sus autores (de la lente al visor). Todos ellos utilizan su día a día mundano como referencia para sus historias desde donde reflejan al lector estos sentimientos «negativos» que acompañan a lo cotidiano. En torno a esta premisa de «apertura al mundo» y en relación al cine de la japonesa Naomi Kawase, una de las directoras que ha hecho suyo el precepto de la Nouvelle Vague de la relación entre cine y vida, ${ }^{37}$ Gonzalo de Luca escribe:

¿De qué conservan memoria? Del tiempo en que uno posa su mirada en unas baldosas, en un cristal o en una pared, maravillado ante el menor movimiento. Expectación del cine y de un mundo que se abre con la cámara. La vida banal, en sus aspectos más circunstanciales e inmediatos, se percibe como algo precioso, desde el deseo y tal vez desde el capricho. ${ }^{38}$

En esa búsqueda de naturalidad y espontaneidad, en ese intento por representar la realidad de la forma más fidedigna posible, la corriente de la Nouvelle Manga decide privilegiar a la imagen por encima del texto. ${ }^{39} \mathrm{Al}$ igual que en la Nouvelle Vague, en la Nouvelle Manga nos

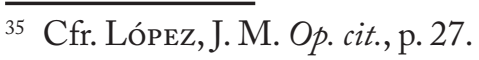

${ }^{36}$ Handke, P. Ensayo sobre el cansancio. Trad. Eustaquio Barjau. Madrid, Alianza Editorial, 2006, p. 39.

37 «Las películas y la vida están siempre juntas y avanzan como dos ruedas en paralelo». Masterclass ofrecida por la cineasta japonesa Naomi Kawase, invitada de honor del Festival de Cine 4+1 FUNDACIÓN MAPFRE en la Cineteca Nacional de Ciudad de México el 29 de octubre de 2011. Disponible en https://www. youtube.com/watch?v=sQm2a6WsjdU (Consultado el 27 de mayo de 2014).

38 De lucas, G. «El cine tiembla», en López, J. M. (ed.). Op. cit., p. 33.

39 A pesar de la inquebrantable separación entre imagen y texto en el medio de expresión del tebeo, los autores poseen cierto margen para decantar el peso de su narración sobre uno u otro elemento. La Nourvelle Manga se insertaría dentro de esa tradición de tebeos que han privilegiado el dibujo por el dibujo, dejando a un lado el diálogo o, al menos, restándole importancia con respecto a la imagen. Para un análisis detallado sobre la relación entre texto e imagen en el cómic, véase: EIsnER, W. El comic y el arte secuencial. Barcelona, Norma, 2002, pp. 125-126.
} 

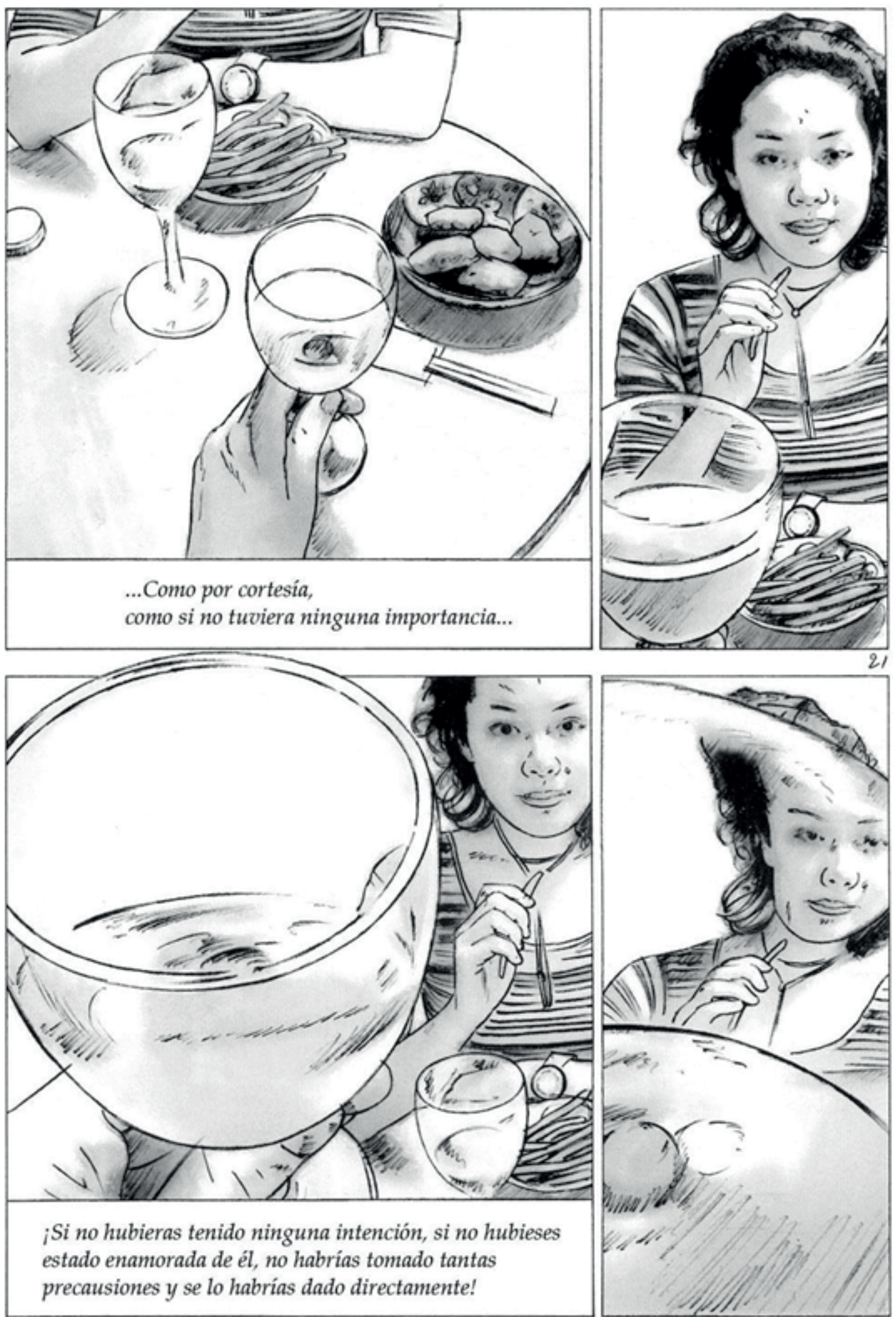

¡Si no hubieras tenido ninguna intención, si no hubieses estado enamorada de él, no habrias tomado tantas precausiones y se lo habrías dado directamente!

FIG. 4. Boilet, F. (2003). Op. cit., p. 25. 
encontraremos escenas de tiempo lento, con escaso diálogo, a veces, incluso, inexistente o carentes de importancia. La Nouvelle Manga, al igual que lo fue en su día la Nouvelle Vague, se trata de un tipo de representación que obliga al lector a pararse, a mirar y a pensar en lo que mira. Lo que se muestra se sugiere más que se explica.

El público asiduo únicamente a las corrientes del mainstream rápidamente se aburre y cuestiona: «ipor qué durante tanto tiempo el mismo plano?» o «ंqué se oculta tras ese gesto?». La repetición de la fórmula narrativa nudo-desenlace-final de ese tipo de producciones obliga a instaurar una causalidad inexistente entre los espectadores o lectores del cine y el cómic comercial. Frente a ello, la protagonista de la película Vivre sa vie de Godard acaricia el borde del vaso con su dedo durante un plano que dura dos, tres, cuatro, cinco minutos. ¿La explicación? No hay gran cosa que decir al respecto: cualquiera puede quedarse en $\mathrm{Ba}-$ bia, sin pensar necesariamente en nada en concreto, dejando pasar el tiempo sin el menor interés por recuperarlo o «aprovecharlo», como, recordemos, parece ser premisa básica de la sociedad de la autoexplotación. En uno de los Kôan ${ }^{40}$ más citados de la historia se narra el episodio entre un maestro zen y su discípulo. Cuando el monje preguntó a su maestro por el significado de las cosas, este último levantó su bastón. El discípulo, a raíz del acto, elaboró un refinado discurso teológico en torno al gesto que acaba de observar. El maestro contestó que se trataba de una explicación demasiado enrevesada. El discípulo preguntó, pues, por su verdadero significado, a lo que el monje respondió alzando de nuevo el bastón. Del mismo modo, si alguien preguntase qué se esconde detrás de las novelas gráficas de los autores de la Nouvelle Manga la respuesta sería sencillamente abrir el cómic en cuestión por la primera página y comenzar a leer.

\footnotetext{
${ }_{40}$ Problema que, en el Budismo Zen, el maestro plantea al alumno a fin de guiar a su alumno en su aprendizaje. Véase: Lanzaco Salafranca, F. Introducción a la cultura japonesa. Pensamiento y religión. Ed. cit., pp. 271-272.
} 


\section{Bibliografía}

Austruc, A. «Camera stylo L’Ecran Francais», art. cit., en Romaguera i Ramió, J. Fuentes y documentos del cine. Barcelona, GG Mass media, 1980.

Agustí Farré, A. «Autobiografía y Autoficción», en Sociedad Española de Estudios Literarios de Cultura Popular, n. ${ }^{\circ} 6$ (2006).

Angulo, J. «Antes de la revolución. El cine Francés de 1944 a 1954», en F. Heredero, C. y Enrique Montender, J. (ed.) En torno a la Nouvelle Vague. Rupturas y horizontes de la modernidad. Valencia, Festival internacional del cine de Gijón ediciones La Filmoteca, 2002.

BAtisde, J. «Entretien avec Frédéric Boilet» entrevista realizada entre Paris y Tokio de octubre a diciembre de 2001. Disponible en http://www.boilet.net/fr/nouvellemanga bilan $1 . h t m l$

B. David. Epiléptico. la ascensión del gran mal.Trad. Lorenzo Fernández Díaz. Madrid, Sins Entido, 2009.

Berndt, J. El fenómeno manga. Trad. J. A. Bravo. Barcelona, Martínez Roca, 1996

Berrio, J. Miércoles. Madrid, Sins Entido, 2012.

Boilet, F. «Manifiesto Nouvelle Manga», 2001. Disponible en http://www.boilet. net/es/nouvellemanga manifeste 1

—La espinaca de Yukiko.Trad. Enrique Sánchez Abulí. Tarragona, Ponent Mon, 2003. -Japón. Trad. Xavier Hérbet y Naomiki Satô. Tarragona, Ponent Mon, 2005.

- Tokio es mi jardin. Trad. Kaotu Sekizumi, Tarragona, Ponent Mon, 2005.

—Love Hôtel. Angoulême, Ego comme x, 2005.

-Mariko Parade. Trad.Elizabeth Tiernan. Tarragona, Ponent Mon, 2006.

—Ellas. Trad. Lorenzo Díaz. Tarragona, Ponent Mon, 2007.

Campi, T. y Zabus, V. Gente corriente (Epílogo). Trad. Natalia Mosquera Sarmiento. Barcelona, La Cúpula, 2014.

Eisner, W. El comic y el arte secuencial. Barcelona, Norma, 2002.

Gascal, L. y Mensuro, A. La pintura en el cómic. Madrid, Cátedra, 2014.

Handke, P. Ensayo sobre el cansancio. Trad. Eustaquio Barjau. Madrid, Alianza Editorial, 2006. 
Hernández Ranza, O. «Nouvelle Manga, mon amour. Reflexiones sobre la narración gráfica de historias cotidiana», en Ballaterra Journal of Teaching and Learning Language and Literature, n. 2 (2010).

Hernández Sánchez, D. «Denotando acontecimientos. Arte y destrucción en la novela gráfica», en Revista de Occidente, n. 429 (2017).

Larcenet, M. Los combates cotidianos (Epílogo). Trad. Enrique Sánchez Abulí. Barcelona, Norma, 2012.

LARDín, R. El principio del fin: Tendencias y efectivos del novísimo cine japonés. Barcelona, Paidós Ibérica, 2003.

López, J. M. «El cine en el umbral», en López J. M. (ed.) Naomi Kawase. El cine en el umbral. Madrid, T\&B editores, 2008.

McCloud, S. Entender el cómic. El arte invisible. Trad. Enrique Sánchez Abulí. Bilbao, Astiberri, 2009.

Mazur, D. y Alezander, D. Cómics. Una historia global, desde 1968 hasta hoy. Trad. Antonio Díaz Pérez. Barcelona, Blume, 2014.

Nananan, K. Blue. Trad. Xavier Hérbet y Naomiki Satô. Tarragona, Ponent Mon, 2004.

—El amor duele. Trad. Xavier Hérbet y Naomiki Satô. Tarragona, Ponent Mon, 2009.

Pazó, J. «Natsume Sōseki, el humilde campeón de las letras japonesas», en Cid Lucas, F. (ed.), La narrativa japonesa: Del «Genji Monogatari» al manga. Málaga, Cátedra, 2014.

Pons, A. Savater, F. y Casariego Córdoba, M. «Del tebeo a la novela gráfica. E1 cómic y sus relaciones con la literatura y el cine». Ciclo de conferencias organizado por la Fundación MAPFRE, 27 de septiembre de 2011. Disponible en https://www. youtube.com/watch?v=ilvaPm7AeD4

RocA, P. Arrugas. Bilbao, Astiberri, 2013.

Satrapi, M. Persépolis. Trad. Albert Agut. Barcelona, Norma, 2007.

Takahama, K. Monokuro kinderbook.Trad.Keiko Suzuki y M. Barrera. Tarragona, Ponent Mon, 2003. 
TAniguchi, J. El olmo del Cáucaso. Trad.Shizuka Shimoyama y Miguel Ángel Ibáñez Muñoz. Tarragona, Ponent Mon, 2004.

—Barrio lejano. Trad. Keiko Suzuki y M. Barrera. Tarragona, Ponent Mon, 2005.

- La época de Botchan. Trad. Shizuka Shimoyama, Miguel Ángel Ibáñez Muñoz. Tarragona, Ponent Mon, 2005.

—Mi año. Trad. Elia Maqueda López. Tarragona, Ponent Mon, 2009.

-Un zoo en invierno. Trad. Víctor Illera Kanaya. Tarragona, Ponent Mon, 2010.

_Furari.Trad. Víctor Illera Kanaya. Tarragona, Ponent Mon, 2011.

—Los años dulces. Tomos 1 y 2. Trad. Víctor Illera Kanaya. Tarragona, Ponent Mon, 2013.

- El caminante. Trad. Shizuka Shimoyama, Miguel Ángel Ibáñez Muñoz, Víctor Illera y Ana Millán. Tarragona, Ponent Mon, 2015.

Zunzunegui, S. «La "política de autores" y la noción de "puesta en escena" en los Cahiers du Cinéma entre 1952 y 1965», en F. Heredero, C. y Montender, J. E. (eds.), En torno a la Nouvelle Vague. Rupturas y horizontes de la modernidad. Valencia, Festival internacional del cine de Gijón, Ediciones La Filmoteca, 2002. 